\section{OPEN ACCESS}

Edited by:

Luis Garcia-Marcos,

Universidad de Murcia, Spain

Reviewed by:

Cyril Etienne Schweitzer,

Université de Lorraine, France

Antonio Martinez-Gimeno,

Complejo Hospitalario de Toledo,

Spain

Enrico Lombardi,

Meyer Pediatric UniversityHospital, Italy

*Correspondence: Marcus H. Jones mhjones@pucrs.br

Specialty section:

This article was submitted to Pediatric Pulmonology, a section of the journal

Frontiers in Pediatrics

Received: 28 August 2017 Accepted: 04 December 2017 Published: 18 December 2017

Citation:

Jones $\mathrm{MH}$, Roncada $\mathrm{C}$ Fernandes MTC, Heinzmann-Filho JP,

Sarria Icaza EE, Mattiello $R$, Pitrez PMC, Pinto LA and Stein RT

(2017) Asthma and Obesity in

Children Are Independently Associated with Airway Dysanapsis.

Front. Pediatr. 5:270.

doi: 10.3389/fped.2017.00270

\title{
Asthma and Obesity in Children Are Independently Associated with Airway Dysanapsis
}

\begin{abstract}
Marcus H. Jones ${ }^{1 *}$, Cristian Roncada ${ }^{1}$, Morgana Thais Carollo Fernandes ${ }^{1,2}$, João Paulo Heinzmann-Filho', Edgar Enrique Sarria Icaza ${ }^{3}$, Rita Mattiello', Paulo Marcio C. Pitrez ${ }^{1}$, Leonardo A. Pinto ${ }^{1}$ and Renato T. Stein ${ }^{1}$
\end{abstract}

'Laboratory of Respiratory Physiology, Infant Center, School of Medicine, Pontifícia Universidade Católica do Rio Grande do Sul (PUCRS), Porto Alegre, Brazil, '2 School of Nursing, Centro Universitário Ritter dos Reis, Porto Alegre, Brazil,

${ }^{3}$ School of Medicine, Universidade de Santa Cruz, Santa Cruz do Sul, Brazil

Background: An increase in the prevalence of overweight and asthma has been observed. Both conditions affect negatively lung function in adults and children. The aim of this study was to analyze the effect of overweight and asthma on lung function in children.

Methods: We designed a case-control study of healthy and asthmatic subjects nested within an epidemiological asthma prevalence study in children between 8 and 16 years of age. The effect of asthma and overweight on lung function was assessed by impulse oscillometry and spirometry obtained at baseline and 10-15 min after salbutamol.

Results: 188 children were recruited, 114 (61\%) were asthmatics and 72 (38\%) were overweight or obese. Children with asthma and overweight had a higher FVC $(+1.16 z$ scores, $p<0.001)$ and higher FEV 1 (+0.79 z scores, $p=0.004)$ and lower FEV $1 / F V C$ $(-0.54 z$ scores, $p=0.008)$ when compared to healthy controls. Compared to normal weight asthmatics, the overweight had higher FVC (+0.78 $z$ scores, $p=0.005)$ and lower $\mathrm{FEV}_{1} / \mathrm{FVC}(-0.50 z$ scores, $p=0.007)$. In the multivariate analysis, overweight was associated with an increase of 0.71 and $0.44 z$ scores in FVC and $\mathrm{FEV}_{1}$, respectively, and a reduction in $\mathrm{FEV}_{1} / \mathrm{FVC}$ by $0.40 z$ scores $(p<0.01$ for all). Overweight had no effect on maximal flows and airway resistance at baseline, and this was not modified by inhalation of a bronchodilator. Asthma was also associated with higher post-BD FVC $(0.45$ $z$ scores, $p=0.012)$ and $\mathrm{FEV}_{1}(0.35 z$ scores, $p=0.034)$ but not with $\mathrm{FEV}_{1} / \mathrm{FVC}$ and $\mathrm{FEF}_{25-75 \%}$. Two-way analysis of variance did not detect any interaction between asthma and overweight on lung function variables before or after bronchodilator.

Conclusion: Our results suggest that asthma and overweight are independently associated with airway dysanaptic growth in children which can be further scrutinized using impulse oscillometry. Overweight contributed more to the reduction in $\mathrm{FEV}_{1} / \mathrm{FVC}$ than asthma in children without increasing airway resistance. Spirometry specificity and sensitivity for obstructive diseases may be reduced in populations with high prevalence of overweight. Adding impedance oscillometry to spirometry improves our understanding of the ventilatory abnormalities in overweight children.

Keywords: lung function, asthma, children, overweight, obesity 


\section{INTRODUCTION}

Asthma and obesity are common chronic diseases that affect the physical, social, and mental health of individuals. Obesity, characterized by the accumulation of body fat, predisposes to several health risks in children $(1,2)$.

In Brazil, as well as in many countries, the prevalence of obesity in children and adolescents has increased in recent decades (3). Data from Brazilian databases show that 33\% of children between 5 and 9 years are currently considered overweight, and $16 \%$ of boys and $11 \%$ of girls were considered obese (4).

In the same period, there was an increase in the prevalence of asthma in children and adolescents in Brazil $(5,6)$ with substantial increase in morbidity and health costs (7). Quite consistently, some studies suggest a link between obesity and asthma $(8,9)$. However, the causal relationship remains controversial and studies exploring the mechanisms involved are required to clarify this association (10-12).

Interestingly, both conditions can negatively affect lung function. In adults, the relationship between overweight/obesity and pulmonary function seems to be well established and most studies detected a reduction in FVC and $\mathrm{FEV}_{1}$ in subjects with overweight and obesity (13-15). However, in children, the relationship between overweight and lung function is less clear. Systematic reviews have shown a significant reduction in lung volumes (16), and an increased FVC and $\mathrm{FEV}_{1}$ in overweight and obese children $(17,18)$. Although several studies did not report lower flows $(19,20)$, some studies have detected a deleterious effect on lung volumes and flows with increased body mass index (BMI) in children (21-24). This pattern of disproportionate but physiologically normal lung growth characterized by an increase in expired volume that is not accompanied by a comparative increase in maximal flows was termed dysanaptic growth (25). More recently, the pooled analysis of several cohorts from healthy and asthmatic children and adolescents confirmed the association of overweight or obesity to higher baseline FVC, TLC, and FEV and lower maximal flows and $\mathrm{FEV}_{1} / \mathrm{FVC}$ (26). These authors also report an association between the presence of dysanapsis and respiratory morbidity in asthmatic children. Still, most studies show results from baseline lung function only, and it is possible that some degree of bronchoconstriction is present, particularly in children with more persistent asthma. Bronchoconstriction, if present, would amplify the mismatch between FVC and $\mathrm{FEV}_{1}$.

In this context, where the preferred parameter to detect obstruction (i.e., $\mathrm{FEV}_{1} / \mathrm{FVC}$ ratio) is similarly affected by either asthma or overweight, the analysis of airway resistance would be an important alternative tool to evaluate whether the observed reduced ratio is an expression of a true obstructive disorder or simply a variant of normality. The aim of this study was to analyze the specific effects of overweight and asthma on lung function in school age children, comparing the results by spirometry and impulse oscillometry, before and after bronchodilation.

\section{MATERIALS AND METHODS}

\section{Subjects}

We designed a case-control study nested within an epidemiological investigation of asthma prevalence in 8-16 years old children attending public schools in Porto Alegre, Brazil. Briefly, parents responded a respiratory health questionnaire and asthma was defined as a positive answer to all the following questions: "Has your child ever had asthma?" and "Did your child have wheeze in the previous year?" and "Did you use asthma medications in the previous year" (for this question a checklist of specific asthma medications was shown to mothers). Asthmatic children identified by the questionnaire were invited to participate in a lung function study. Classmates without asthma, according to the same questionnaire, were invited to participate in the study as healthy controls. The exclusion criteria were a history of cardiovascular or immune deficiency conditions, presence of other chronic respiratory diseases, recent asthma or rhinitis exacerbations, and diagnosis of an acute respiratory infection or use of oral steroids in the previous month.

\section{Anthropometric Measurements}

Children were weighed with a calibrated scale after removing heavy clothing and shoes, with feet in parallel, head in the midline and arms along the body. Weight was recorded to the nearest $0.1 \mathrm{~kg}$. For the measurement of height, a stadiometer (Altura Exata $^{\circledR}$, Belo Horizonte, Brazil) was used. The measurements of height and weight were used to calculate BMI. $z$ scores for BMI and percentiles were calculated using the British 1990 Growth Reference Centiles (27). The classification for normal weight, overweight, and obesity was based on sex- and age-specific cutoff points adopted by the International Obesity Task Force (28). This classification uses centile curves that at age 18 years pass through the widely used BMI cutoff points of 25 and $30 \mathrm{~kg} / \mathrm{m}^{2}$ for overweight and obesity, respectively. For example, in an 11-year-old child, the BMI cutoff point for overweight is 20.55 for males and 20.74 for females.

\section{Asthma Classification}

Asthma severity was defined by GINA (29) classification standards, based on the treatment required to achieve control of the symptoms. Asthma control was also assessed by a validated Brazilian Portuguese version of the Childhood Asthma Control Test (c-ACT) $(30,31)$.

\section{Lung Function Tests}

Pulmonary function tests were performed in the Laboratory of Respiratory Physiology by trained professionals, in a quiet environment at room temperature, using an incentive Koko spirometer (Ferraris, USA), and an Impulse Oscillometry System (IOS, CareFusion, Yorba Linda, CA, USA). The order of the lung function tests was IOS, spirometry, bronchodilator, IOS, and spirometry. All evaluations were performed at baseline and 10-15 min after four puffs of salbutamol using a spacer (AeroChamber ${ }^{\mathrm{TM}}$ ), in accordance with the guidelines of the American Thoracic Society and European Respiratory Society (32).

\section{Spirometry}

The spirometry was performed in accordance with the guidelines published by the ERS/ATS (32). At least three acceptable and reproducible maximal flow-volume curves were obtained 
before and after using a bronchodilator (Salbutamol, $400 \mu \mathrm{g}$ ). Results were transformed to $z$ scores according to international reference values (GLI 2012) that adjust for height, age, ethnicity, and sex (33).

\section{Impulse Oscillometry}

Measurements were performed and analyzed in accordance with ERS/ATS guidelines (34). Subjects were asked to close their lips around the mouthpiece and cheeks were supported. A nasal clip was used during all the measurements. If artifacts were detected the measurement was repeated until three acceptable curves were obtained. Measurements of respiratory impedance were made at 5 and $20 \mathrm{~Hz}$ and the mean values of resistance (R5 and R20) and reactance (X5) from the best three trials were used for the analysis. Results were transformed to $z$ scores from reference values (35).

\section{Statistics and Ethics}

Demographic data are presented by descriptive statistics. Continuous data are summarized by arithmetic means and SD, or by median and quartiles. Qualitative and quantitative variables were described, respectively, by mean and SD or median/range or frequency/percentage. Groups were compared by the Student's $t$-test. Correlation between BMI and lung function variables was tested by the Pearson test. Two-way analysis of variance (ANOVA) and Bonferroni post hoc test were used to compare lung function variables in subgroups stratified by overweight and asthma. The effect of overweight and asthma on lung function was evaluated by multiple linear regressions using lung function expressed as $z$ scores as the dependent variables, and overweight and asthma as dichotomic independent variables. All tests were two sided and significance was set at the $95 \%$ level, and the analyses were performed on SPSS, version 22.0 (SPSS, Chicago, IL, USA). The study was approved by the Human Ethics Committee of the Pontifícia Universidade Católica do Rio Grande do Sul (PUCRS), Porto Alegre, Brazil. Parental written informed consent was obtained from all participants.

\section{RESULTS}

The demographics of the subjects enrolled in the study are presented in Table 1. Of the 188 children, 97 (52\%) were females, 114 (61\%) had asthma, 49 (26\%) were classified as

TABLE 1 | Clinical and demographic characteristics of the sample.

\begin{tabular}{lcc}
\hline & $\begin{array}{c}\text { Healthy controls, } \\
\boldsymbol{n}=\mathbf{7 4}(\mathbf{3 9 \% )}\end{array}$ & $\begin{array}{c}\text { Asthma, } \\
\boldsymbol{n}=\mathbf{1 1 4}(\mathbf{6 1} \%)\end{array}$ \\
\hline Ethnicity (\% white) & $57(77)$ & $70(61)$ \\
Sex (\% male) & $33(45)$ & $58(51)$ \\
Age (years) & $11.17 \pm 1.19$ & $11.10 \pm 1.10$ \\
Weight (kg) & $43.69 \pm 10.60$ & $44.52 \pm 13.29$ \\
Weight (z score) & $0.78 \pm 1.00$ & $0.86 \pm 1.21$ \\
Height (cm) & $146.97 \pm 8.35$ & $146.55 \pm 8.46$ \\
Height (z score) & $0.36 \pm 0.92$ & $0.33 \pm 0.94$ \\
Body mass index (BMI) & $19.98 \pm 3.46$ & $20.49 \pm 4.72$ \\
BMl (z score) & $0.86 \pm 1.06$ & $0.90 \pm 1.37$
\end{tabular}

overweight, and $23(12 \%)$ as obese. The BMI $z$ score ranged between -2.2 and 3.95. Due to the small number of obese children, all statistical analyses were performed combining all the 72 overweight and obese subjects. The range for age and height were $8.3-14.8$ years and $122-171 \mathrm{~cm}$, respectively. Most of the subjects $(127 / 188,67 \%)$ were classified as white. There were no statistical differences between children with asthma and controls regarding anthropometry and ethnicity. Among 114 asthmatic children, reliable information regarding asthma severity and asthma control were obtained in 101 (89\%) and $100(88 \%)$, respectively. Children with asthma were classified as having intermittent $39(39 \%)$ or mild persistent asthma $(41,41 \%)$ and the remaining $21(21 \%)$ with persistent moderate asthma. None had severe persistent asthma. Regarding asthma control $89(89 \%)$ had partially or uncontrolled asthma in the previous 12 months.

\section{Baseline and Post-BD Lung Function}

The results of lung function tests are presented in Table 2, stratified by asthma and by BMI grade. There was no association between asthma severity or asthma control (c-ACT) and BMI or lung function. At baseline, children with asthma had significantly lower $\mathrm{FEF}_{25-75 \%}$ and $\mathrm{FEV}_{1} / \mathrm{FVC}$ and higher R5 and R20 and lower reactance $\mathrm{X} 5$ ( $p<0.01$ for all analysis). $\mathrm{FEV}_{1}$ was similar in asthmatic and healthy controls. Children with asthma had significantly higher bronchodilator response in $\mathrm{FEV}_{1}$ and $\mathrm{FEF}_{25-75 \%}$; 6.6 versus $3.3 \%(p<0.01)$ and 23.3 versus $12.2 \%(p<0.001)$, respectively. Children with and without asthma had similar reduction in R5 and R20 with bronchodilator.

Stratifying the subjects by BMI grade we detected a significant positive effect of overweight on $\mathrm{FEV}_{1}, \mathrm{FVC}$, and a reduction in $\mathrm{FEV}_{1} / \mathrm{FVC}(p<0.01$ for all). These differences when compare to non-overweight children were maintained after bronchodilator. Being overweight was not associated with lower maximal flows or higher airway resistance. Overweight children had comparable bronchodilator response in $\mathrm{FEV}_{1}, \mathrm{FEF}_{25-75 \%}, \mathrm{R} 5, \mathrm{R} 20$, and X5 when compared to normal weight children.

\section{Stratified Analysis of Post-BD Lung Function}

To explore the effects detected in the previous analysis the sample was stratified by asthma and overweight in four subgroups: healthy controls, controls overweight, asthma, and asthma overweight. The analysis was performed on lung function post-bronchodilator to minimize the effect of bronchial tone on the results and is shown in Figure 1. Results are from two-way ANOVA with post hoc Bonferroni pairwise analysis. Children with asthma who were overweight had a FVC that was $1.16 z$ scores higher than healthy controls, equivalent of $+362 \mathrm{~mL}$ or $+13.6 \%(p<0.001)$. They also had higher $\mathrm{FEV}_{1}(+0.79 z$ scores, $9.6 \%, p=0.004)$ and lower $\mathrm{FEV}_{1} / \mathrm{FVC}(-0.54 z$ scores, $p=0.008)$ values when compared to healthy controls. Compared to normal weight asthmatics, the overweight had higher FVC (+0.78 $z$ scores, $p=0.005)$ and lower FEV1/FVC $(-0.50 z$ scores, $p=0.007)$. The 
TABLE 2 | Baseline and post-bronchodilator lung function of 188 school age children stratified by asthma and by body mass index (BMI) classification.

\begin{tabular}{|c|c|c|c|c|}
\hline \multirow[b]{2}{*}{ Baseline } & \multicolumn{2}{|c|}{ Stratified by asthma } & \multicolumn{2}{|c|}{ Stratified by BMI classification } \\
\hline & Healthy controls $(n=74)$ & Asthma $(n=114)$ & Normal weight $(n=116)$ & Overweight $(n=72)$ \\
\hline $\mathrm{FEV}_{1}$ & $-0.023 \pm 0.906$ & $-0.030 \pm 1.051$ & $-0.175 \pm 0.907$ & $0.211 \pm 1.083^{\star \star}$ \\
\hline FVC & $-0.014 \pm 0.898$ & $0.311 \pm 1.096^{*}$ & $-0.074 \pm 0.889$ & $0.596 \pm 1.117^{\star \star}$ \\
\hline $\mathrm{FEV}_{1} / \mathrm{FVC}$ & $-0.093 \pm 0.746$ & $-0.560 \pm 0.884^{\star \star}$ & $-0.238 \pm 0.828$ & $-0.600 \pm 0.872^{\star \star}$ \\
\hline $\mathrm{FEF}_{25-75 \%}$ & $0.006 \pm 0.912$ & $-0.485 \pm 1.029^{\star \star}$ & $-0.248 \pm 0.990$ & $-0.362 \pm 1.047$ \\
\hline $\mathrm{R} 5$ & $0.467 \pm 0.722$ & $0.852 \pm 0.794^{\star \star}$ & $0.636 \pm 0.786$ & $0.804 \pm 0.783$ \\
\hline $\mathrm{R} 20$ & $0.296 \pm 0.543$ & $0.643 \pm 0.646^{\star \star}$ & $0.542 \pm 0.632$ & $0.450 \pm 0.625$ \\
\hline X5 & $-0.168 \pm 0.927$ & $-0.775 \pm 1.930^{\star \star}$ & $-0.482 \pm 1.760$ & $-0.623 \pm 1.419$ \\
\hline \multicolumn{5}{|l|}{ Post-BD } \\
\hline $\mathrm{FEV}_{1}$ & $0.188 \pm 0.786$ & $0.543 \pm 1.134^{*}$ & $0.232 \pm 0.901$ & $0.682 \pm 1.151^{\star \star}$ \\
\hline FVC & $0.056 \pm 0.879$ & $0.529 \pm 1.278^{\star \star}$ & $0.075 \pm 0.965$ & $0.781 \pm 1.312^{\star \star}$ \\
\hline $\mathrm{FEV}_{1} / \mathrm{FVC}$ & $0.155 \pm 0.700$ & $-0.005 \pm 0.770$ & $0.204 \pm 0.709$ & $-0.182 \pm 0.747^{\star \star}$ \\
\hline $\mathrm{FEF}_{25-75 \%}$ & $0.368 \pm 0.797$ & $0.309 \pm 0.909$ & $0.375 \pm 0.803$ & $0.263 \pm 0.960$ \\
\hline R5 & $0.067 \pm 0.563$ & $0.305 \pm 0.639^{*}$ & $0.191 \pm 0.676$ & $0.244 \pm 0.522$ \\
\hline $\mathrm{R} 20$ & $0.112 \pm 0.401$ & $0.381 \pm 0.495^{\star \star}$ & $0.310 \pm 0.478$ & $0.222 \pm 0.475$ \\
\hline X5 & $0.364 \pm 0.746$ & $-0.026 \pm 1.949$ & $0.066 \pm 1.925$ & $0.223 \pm 0.859$ \\
\hline
\end{tabular}

All variables expressed as z scores.

FVC, forced vital capacity; $F E V_{1}$, forced expiratory volume in $1 \mathrm{~s}$; $F E F_{25-75 \%}$, forced expiratory flow at 25-75\% of FVC;

$R 5$, resistance at $5 \mathrm{~Hz} ; \mathrm{R} 20$, resistance at $5 \mathrm{~Hz} ; \mathrm{X} 5$, reactance at $5 \mathrm{~Hz}$.

Values expressed as mean $\pm S D$.

${ }^{*} p<0.05$.

${ }^{* *} p<0.01$.
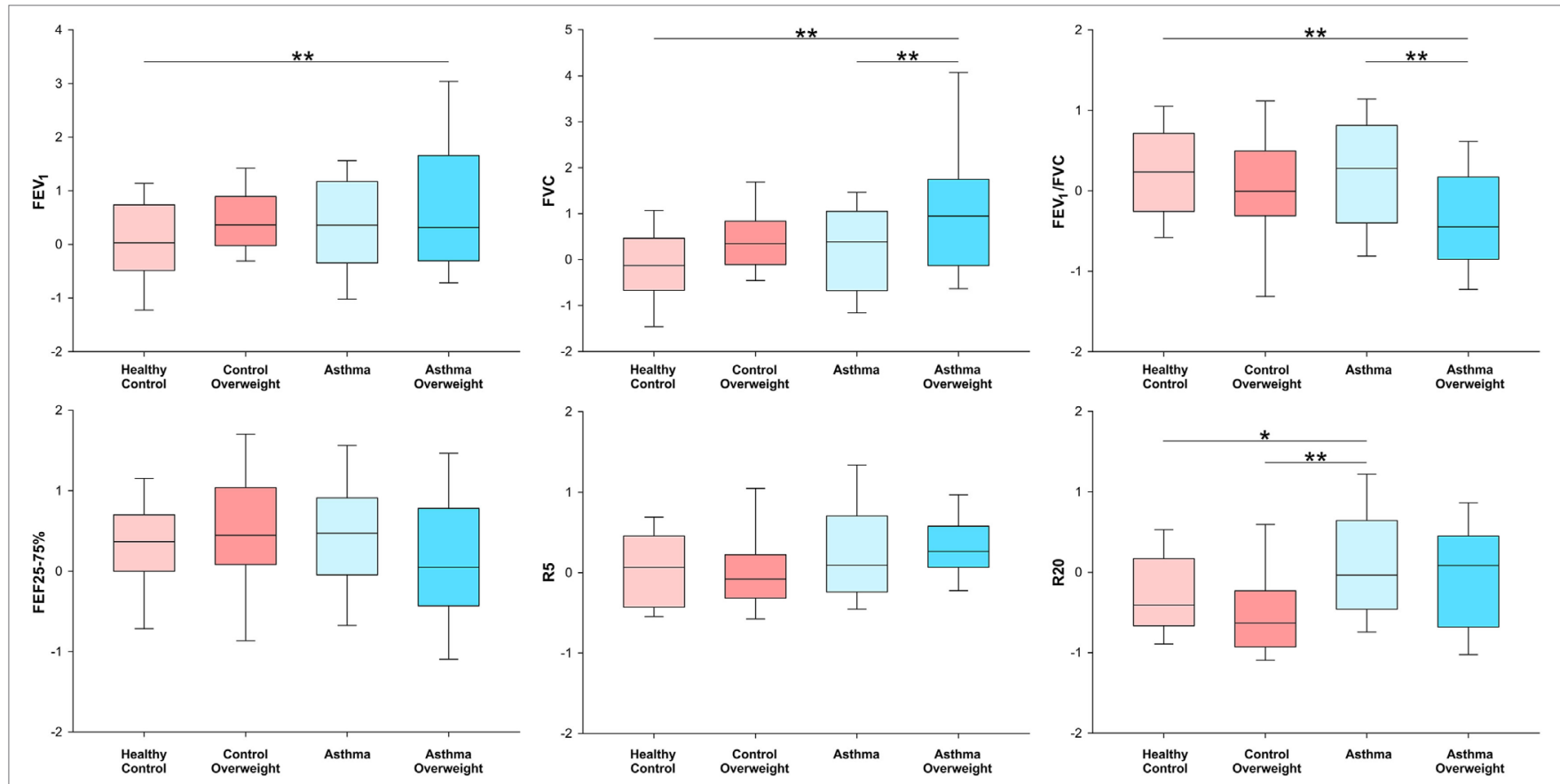

FIGURE 1 | Box-plots showing median and interquartile ranges for FEV 1 , FVC FEV $/$ FVC, FEF $25-75 \%$, R5, and R20 stratified in four subgroups by the presence of overweight and asthma. ${ }^{*} p<0.05$ and ${ }^{* *} p<0.01$ for analysis of variance with post hoc Bonferroni pairwise analysis.

magnitude of the effect of overweight in asthmatic subjects, after adjusting for height, age, and sex was $+234 \mathrm{~mL}(8.7 \%, p<0.01)$ in $\mathrm{FVC}$ and a reduction of $3.4 \%$ in $\mathrm{FEV}_{1} / \mathrm{FVC}(p<0.01)$ when compared to normal weight asthmatic children. Normal weight asthmatics had higher post-BD R20 compared to healthy controls $(+0.27 z$ scores, $p=0.013)$ and overweight controls $(+0.38 z$ scores, $p=0.003)$.

\section{Multivariate Analysis of the Effect of Overweight and Asthma on Lung Function}

Figure 2 and Table 3 show the magnitude of the effect of overweight and asthma on lung function estimated by multivariable linear regression, with healthy controls as the reference group. The presence of overweight was associated with an increase of $0.7 z$ scores in $\mathrm{FVC}$, equivalent to $210 \mathrm{~mL}$ or $7.5 \%(p<0.001)$. 


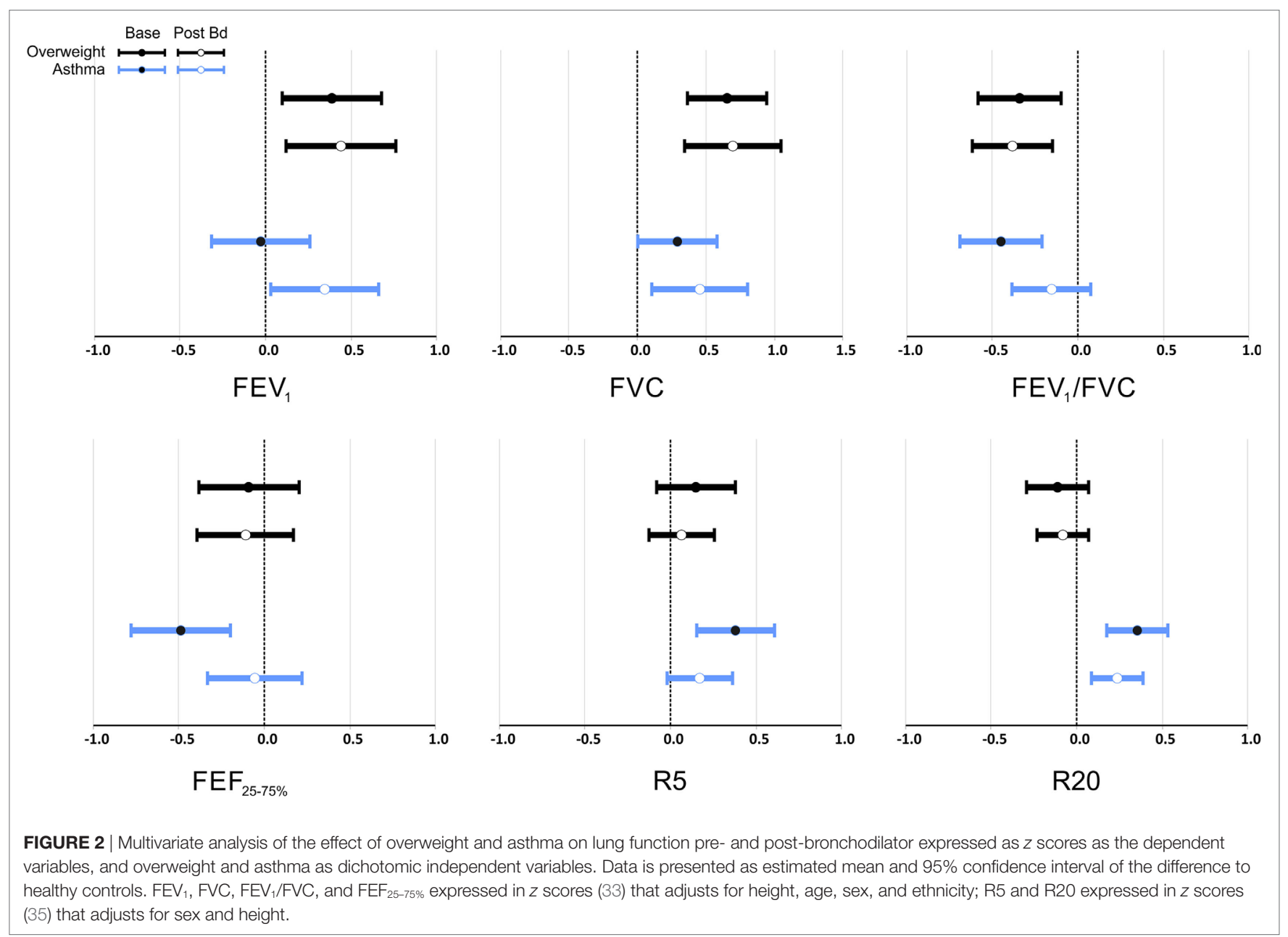

$\mathrm{FEV}_{1}$ was also significantly higher with overweight, but the magnitude of the difference was smaller in comparison to FVC: +0.39 at baseline and $+0.44 z$ scores post-BD ( $p<0.01$ for both). In addition, overweight had a significantly impact on pre- and post-BD $\mathrm{FEV}_{1} / \mathrm{FVC}(p<0.001)$ reducing the ratio by 0.34 and $0.40 z$ scores, respectively. Overweight had no detectable effect on maximal flows and airway resistance at baseline and this was not modified by inhalation of a bronchodilator.

Asthma was also associated with significantly higher FVC, $0.29 z$ scores $(p=0.047)$ at baseline, and $0.45 z$ scores $(p=0.012)$ after bronchodilator. After bronchodilator $\mathrm{FEV}_{1}$ was $0.35 z$ scores higher in asthmatics $(p=0.034)$, but not at baseline.

At baseline, asthma was associated with significantly lower $\mathrm{FEV}_{1} / \mathrm{FVC}(-0.45 z$ scores, $p<0.001), \mathrm{FEF}_{25-75 \%}(-0.40 z$ scores, $p=0.001)$, and higher R5 and R20 (0.38 and $0.35 z$ scores, $p<0.001$ for both). Reactance was also lower at baseline in children with asthma $(-0.6 z$ scores, $p=0.014)$; this difference was reduced and no longer significant after bronchodilator as well as the differences of $\mathrm{FEV}_{1} / \mathrm{FVC}$, and $\mathrm{FEF}_{25-75 \%}$. After bronchodilator, children with asthma maintained a higher R20 (0.24 z scores, $p=0.002$ ). Two-way ANOVA did not detect any interaction between asthma and overweight on lung function variables before or after bronchodilator.

\section{DISCUSSION}

Our results suggest that both asthma and overweight are associated with airway dysanaptic growth in children which can be further scrutinized using impulse oscilometry. The assessment of lung function by spirometry and forced oscillations, at baseline and after bronchodilator, allowed the analysis of lung growth and airway growth separately and without the confounding influence of bronchial tone. Our results point toward an independent positive effect of BMI and asthma on FVC and $\mathrm{FEV}_{1}$, with a negative effect on $\mathrm{FEV}_{1} / \mathrm{FVC}$ in school age children. However, the discrepancy promoted by overweight and expressed by a lower $\mathrm{FEV}_{1} / \mathrm{FVC}$ is not associated with smaller airways and is also not modified by bronchodilator. Interestingly, after reducing bronchial tone, it becomes clear that the contribution of overweight is substantially bigger than the contribution of asthma in lowering the ratio $\mathrm{FEV}_{1} / \mathrm{FVC}(-0.40$ versus $-0.13 z$ scores, respectively). One could interpret these findings as additional evidence that overweight promotes a lung growth that is different from normal, with a disproportional increase in lung parenchyma (FVC) in comparison to airway (maximal flows and airway resistance). The same pattern of large lungs is seen in swimmers (36), divers (37), and other such athletes, as well as subjects living in high 
TABLE 3 | Multivariate analysis of the effect of overweight and asthma on lung function.

\begin{tabular}{|c|c|c|c|c|c|c|c|c|c|c|c|c|}
\hline \multirow[b]{2}{*}{ FEV $_{1}$} & \multicolumn{6}{|c|}{ Baseline } & \multicolumn{6}{|c|}{ Post-BD } \\
\hline & $\begin{array}{l}\text { Estimated } \\
\text { difference }\end{array}$ & SE & $\begin{array}{l}\text { Lower } \\
\text { bound }\end{array}$ & $\begin{array}{l}\text { Upper } \\
\text { bound }\end{array}$ & $p$-Value & $R^{2}$ & $\begin{array}{l}\text { Estimated } \\
\text { difference }\end{array}$ & SE & $\begin{array}{l}\text { Lower } \\
\text { bound }\end{array}$ & $\begin{array}{l}\text { Upper } \\
\text { bound }\end{array}$ & $p$-Value & $R^{2}$ \\
\hline Overweight & 0.387 & 0.147 & 0.097 & 0.678 & 0.009 & 0.036 & 0.442 & 0.164 & 0.119 & 0.765 & 0.008 & 0.073 \\
\hline Asthma & -0.027 & 0.147 & -0.316 & 0.262 & 0.855 & & 0.346 & 0.162 & 0.026 & 0.667 & 0.034 & \\
\hline \multicolumn{13}{|l|}{ FVC } \\
\hline Overweight & 0.655 & 0.146 & 0.366 & 0.944 & $<0.001$ & 0.119 & 0.706 & 0.180 & 0.352 & 1.061 & $<0.001$ & 0.127 \\
\hline Asthma & 0.291 & 0.146 & 0.004 & 0.578 & 0.047 & & 0.450 & 0.178 & 0.099 & 0.801 & 0.012 & \\
\hline \multicolumn{13}{|l|}{ FEV1/FVC } \\
\hline Overweight & -0.339 & 0.123 & -0.582 & -0.097 & 0.006 & 0.107 & -0.400 & 0.118 & -0.634 & -0.167 & 0.001 & 0.078 \\
\hline Asthma & -0.449 & 0.122 & -0.690 & -0.208 & $<0.001$ & & -0.135 & 0.117 & -0.367 & 0.096 & 0.250 & \\
\hline \multicolumn{13}{|l|}{$\mathbf{F E F}_{2575 \%}$} \\
\hline Overweight & -0.089 & 0.148 & -0.381 & 0.204 & 0.550 & 0.058 & -0.127 & 0.143 & -0.409 & 0.155 & 0.375 & 0.006 \\
\hline Asthma & -0.486 & 0.148 & -0.777 & -0.195 & 0.001 & & -0.041 & 0.141 & -0.320 & 0.239 & 0.774 & \\
\hline \multicolumn{13}{|l|}{ R5 } \\
\hline Overweight & 0.148 & 0.115 & -0.078 & 0.375 & 0.198 & 0.066 & 0.066 & 0.096 & -0.125 & 0.256 & 0.497 & 0.024 \\
\hline Asthma & 0.378 & 0.114 & 0.152 & 0.604 & 0.001 & & 0.171 & 0.095 & -0.017 & 0.360 & 0.075 & \\
\hline \multicolumn{13}{|l|}{ R20 } \\
\hline Overweight & -0.110 & 0.091 & -0.290 & 0.070 & 0.229 & 0.080 & -0.079 & 0.076 & -0.229 & 0.070 & 0.297 & 0.066 \\
\hline Asthma & 0.352 & 0.091 & 0.173 & 0.531 & $<0.001$ & & 0.238 & 0.075 & 0.089 & 0.386 & 0.002 & \\
\hline \multicolumn{13}{|l|}{$\times 5$} \\
\hline Overweight & -0.110 & 0.243 & -0.589 & 0.369 & 0.652 & 0.034 & 0.207 & 0.272 & -0.330 & 0.744 & 0.448 & 0.019 \\
\hline Asthma & -0.602 & 0.242 & -1.078 & -0.125 & 0.014 & & -0.424 & 0.269 & -0.956 & 0.108 & 0.118 & \\
\hline
\end{tabular}

All variables expressed as z scores.

FVC, forced vital capacity; $F E V_{1}$, forced expiratory volume in $1 \mathrm{~s}$; $F E F_{25-75 \%}$, forced expiratory flow at 25-75\% of FVC;

$R 5$, resistance at $5 \mathrm{~Hz}$; $R 20$, resistance at $5 \mathrm{~Hz} ; \mathrm{X} 5$, reactance at $5 \mathrm{~Hz}$.

altitudes (38), and these are findings that have no association with respiratory disease. These observations recommend caution to label a lower $\mathrm{FEV}_{1} / \mathrm{FVC}$ as a true obstructive pattern in overweight children. Another implication is that a lower $\mathrm{FEV}_{1} /$ FVC observed in overweight asthmatic children compared to normal weight asthmatic does not necessarily represent worse clinical respiratory disease.

This is the first study that addresses the impact of overweight and asthma in children comparing two methods that elicit different aspects of lung function, such as spirometry and forced oscillations, before and after bronchodilator. Our findings are in line with studies that reported increased FVC in overweight children (39) but contrast with findings in adults where TLC, $\mathrm{FVC}$, and $\mathrm{FEV}_{1}$ were typically reduced (40). However, the effect of weight on lung function seems to be modified by the duration and severity of obesity (41). In addition, an inverse U-shaped association between BMI and FVC in children have been proposed (42). The most plausible explanation for the absence of these ventilatory abnormalities in our sample of school age children is the small number of subjects with obesity.

The finding of increased FVC in children with asthma is interesting and has been reported previously $(43,44)$. The magnitude of the increase in baseline FVC in our study is similar to that reported for boys in an older study (44) by the order of 3\%, and this effect was smaller than the $6.6 \%$ reported by Strunk et al. (43). The post-bronchodilator FVC was not reported in these studies, precluding any comparison. Since this increase in FVC is not observed in overweight adults, this finding suggests that it is a developmental abnormality that normalizes, or even reverses by the end of somatic growth as suggested by studies in young adults. Our observation of increased post-BD FEV $\mathrm{FE}_{1}$ is intriguing since most studies have reported lower values in children with asthma when compared to healthy controls $(45,46)$. Our interpretation is that the potential reduction in airway caliber due to inflammation and remodeling in asthma was offset by the increase in FVC. In our sample, most of the children with asthma were classified as intermittent or mild persistent, unlikely to have significant and persistent reduction in maximal expiratory flows.

Our results do not establish that asthma and overweight as either the cause or the effect of the increase in lung volume, only its cooccurrence. A follow-up study would provide a more accurate description of these associations. Other factors associated with overweight may be relevant for the observed uneven, dysanaptic lung growth. A higher BMI during childhood is associated with higher inspiratory capacity (19), maximal inspiratory pressure (47), and reduced leg length-to-height ratio (48), all presenting some potential to promote disproportional increases in FVC. These factors are not considered in the current predicted equations and could contribute for underestimation of the FVC.

The results of our study suggest that spirometry, which is widely used in the detection and management of asthma, may have lower specificity and sensitivity for asthma in a predominantly overweight society. The observed $13.6 \%$ increase in FVC, $7.6 \%$ in $\mathrm{FEV}_{1}$, and the decrease of $3.5 \%$ in $\mathrm{FEV}_{1} / \mathrm{FVC}$ in overweight asthmatics is clinically relevant and would have an impact in spirometry, both at diagnostic level and severity classification. 
With the increasing prevalence of obesity in children, we will see not only an excess of diagnoses of obstructive disease due to low $\mathrm{FEV}_{1} / \mathrm{FVC}$ but also a delay to recognize a significant reduction in $\mathrm{FEV}_{1}$ and $\mathrm{FVC}$ due to the use of reference equations not adjusted for body weight. Our data suggest that airway resistance is not increased by overweight and its measurement could be more reliable to assess obstructive diseases in children. Increase in airway resistance was observed in overweight and obese adult subjects (49) but not in preschool children (50). The only study in children that reported an increase in airway resistance with increase in BMI was obtained in children with a history of severe bronchiolitis in the first year of life (51). Our results confirm previous review that airway resistance by IOS can add valuable information in the assessment of respiratory diseases in children (52).

Our study has some limitations that deserve mention. First, the small number of subjects of the study and particularly, the small number of obese and moderate asthmatics subjects enrolled may have reduced power to independently detect the impact of both conditions on lung function. This narrow spectrum was expected from a community-based sample, and it did somehow limit the possible explorations of data in our exploratory study. External validation of the findings, particularly the lack of association of lung function and overweight with clinical outcomes in the asthma group, are needed. In addition, other important variables could not be included in the study; perhaps the most relevant is total lung capacity and residual volume, assessed by plethysmography.

In conclusion, our study demonstrated that both overweight and asthma independently promote an increase in FVC and $\mathrm{FEV}_{1}$ with a resulting decrease in $\mathrm{FEV}_{1} / \mathrm{FVC}$. The results support the concept that overweight promotes an unequal lung growth and that its magnitude is such that it is likely clinically relevant: FVC is $13.6 \%$ higher in children with asthma and overweight when compared to healthy controls and $8.7 \%$ higher when compared to children with asthma and normal weight.

\section{REFERENCES}

1. WHO. Physical status: the use and interpretation of anthropometry. Report of a WHO Expert Committee. World Health Organ Tech Rep Ser (1995) 854:1-452.

2. Kelishadi R, Mirmoghtadaee P, Najafi H, Keikha M. Systematic review on the association of abdominal obesity in children and adolescents with cardiometabolic risk factors. J Res Med Sci (2015) 20:294-307.

3. Ng M, Fleming T, Robinson M, Thomson B, Graetz N, Margono C, et al. Global, regional, and national prevalence of overweight and obesity in children and adults during 1980-2013: a systematic analysis for the Global Burden of Disease Study 2013. Lancet (2014) 384:766-81. doi:10.1016/S0140-6736(14)60460-8

4. Pesquisa de Orçamentos Familiares: 2008-2009. Antropometria e Estado Nutricional de Crianças, Adolescentes e Adultos no Brasil. Brazil: Instituto Brasileiro de Geografia e Estatistica (2010). Available from: https://biblioteca. ibge.gov.br/visualizacao/livros/liv45419.pdf

5. Pitrez PM, Stein RT. Asthma in Latin America: the dawn of a new epidemic. Curr Opin Allergy Clin Immunol (2008) 8:378-83. doi:10.1097/ ACI.0b013e32830fb911

6. Solé D, Wandalsen GF, Camelo-Nunes IC, Naspitz CK, Group I-B. Prevalence of symptoms of asthma, rhinitis, and atopic eczema among Brazilian children and adolescents identified by the International Study of Asthma and Allergies in Childhood (ISAAC) - Phase 3. J Pediatr (Rio J) (2006) 82(5):341-6. doi:10.2223/JPED.1521
Overweight contributed more than asthma to the deficit in $\mathrm{FEV}_{1} /$ FVC without increasing airway resistance. Our results suggest that the effect of overweight is mostly in increasing lung size without any perceptible effect on airway resistance; the effect of asthma is both an increase in lung size and in airway resistance. Our results suggest that spirometry specificity and sensitivity for obstructive diseases may be reduced in populations with high overweight and obesity prevalence. Adding measurements of airway impedance by impulse oscillometry to spirometry may improve our understanding of the true clinically relevance of ventilatory abnormalities in overweight children.

\section{ETHICS STATEMENT}

This study was carried out in accordance with the recommendations of "Comitê de Ética em Pesquisa - CEP" with written informed consent from all subjects. All subjects gave written informed consent in accordance with the Declaration of Helsinki. The protocol was approved by the "Comitê de Ética em Pesquisa da PontifÍcia Universidade Católica do Rio Grande do Sul.”

\section{AUTHOR CONTRIBUTIONS}

MJ and RS designed the study. RS, CR, EI, RM, PP, and MF oversaw all clinical aspects of the study (IRB approval, consenting, sample collection). MJ, CR, JH-F, and EI obtained lung function. CR, RM, and EI developed the cloud-based database. MJ, MF, and $\mathrm{CR}$ analyzed the data. All authors wrote and reviewed the manuscript.

\section{FUNDING}

Funding was provided by a grant from CNPq. Scholarships were provided by CAPES.

7. Roncada C, de Oliveira SG, Cidade SF, Sarria EE, Mattiello R, Ojeda BS, et al. Burden of asthma among inner-city children from Southern Brazil. J Asthma (2016) 53:498-504. doi:10.3109/02770903.2015.1108438

8. Egan KB, Ettinger AS, Bracken MB. Childhood body mass index and subsequent physician-diagnosed asthma: a systematic review and meta-analysis of prospective cohort studies. BMC Pediatr (2013) 13:121. doi:10.1186/14712431-13-121

9. Ross KR, Hart MA. Assessing the relationship between obesity and asthma in adolescent patients: a review. Adolesc Health Med Ther (2013) 4:39-49. doi:10.2147/AHMT.S26707

10. Jay M, Wijetunga NA, Stepney C, Dorsey K, Chua DM, Bruzzese J-M. The relationship between asthma and obesity in urban early adolescents. Pediatr Allergy Immunol Pulmonol (2012) 25:159-67. doi:10.1089/ped. 2012.0145

11. Gibson PG. Obesity and asthma. Ann Am Thorac Soc (2013) 10:S138-42. doi:10.1513/AnnalsATS.201302-038AW

12. Monteiro CA, Conde WL. [Secular trends in malnutrition and obesity among children in the city of Sao Paulo, Brazil (1974-1996)]. Rev Saude Publica (2000) 34:52-61. doi:10.1590/S0034-89102000000700008

13. Ochs-Balcom HM, Grant BJB, Muti P, Sempos CT, Freudenheim JL, Trevisan M, et al. Pulmonary function and abdominal adiposity in the general population. Chest (2006) 129:853-62. doi:10.1378/chest.129.4.853

14. Jones RL, Nzekwu M-MU. The effects of body mass index on lung volumes. Chest (2006) 130:827-33. doi:10.1378/chest.130.3.827 
15. Steele RM, Finucane FM, Griffin SJ, Wareham NJ, Ekelund U. Obesity is associated with altered lung function independently of physical activity and fitness. Obesity (Silver Spring) (2009) 17:578-84. doi:10.1038/oby.2008.584

16. Winck AD, Heinzmann-Filho JP, Soares RB, da Silva JS, Woszezenki CT, Zanatta LB. Effects of obesity on lung volume and capacity in children and adolescents: a systematic review. Rev Paul Pediatr (2016) 34:510-7. doi:10.1016/j. rpped.2016.02.008

17. Yao TC, Tsai HJ, Chang SW, Chung RH, Hsu JY, Tsai MH, et al. Obesity disproportionately impacts lung volumes, airflow and exhaled nitric oxide in children. PLoS One (2017) 12:e0174691. doi:10.1371/journal.pone.0174691

18. Chen Y, Rennie D, Cormier Y, Dosman JA. Waist circumference associated with pulmonary function in children. Pediatr Pulmonol (2009) 44:216-21. doi:10.1002/ppul.20854

19. Rastogi D, Bhalani K, Hall CB, Isasi CR. Association of pulmonary function with adiposity and metabolic abnormalities in Urban minority adolescents. Ann Am ThoracSoc (2014) 11:744-52. doi:10.1513/AnnalsATS.201311-403OC

20. Mahut B, Beydon N, Delclaux C. Overweight is not a comorbidity factor during childhood asthma: the GrowthOb study. Eur Respir J (2012) 39:1120-6. doi:10.1183/09031936.00103311

21. Eisenmann JC, Arnall DA, Kanuho V, Interpretter C, Coast JR. Obesity and pulmonary function in Navajo and Hopi children. Ethn Dis (2007) 17:14-8.

22. Paralikar S, Pathak N, Kathrotia R, Jani M. Assessment of pulmonary functions in obese adolescent boys. Lung India (2012) 29:236. doi:10.4103/ 0970-2113.99106

23. Spathopoulos D, Paraskakis E, Trypsianis G, Tsalkidis A, Arvanitidou V, Emporiadou M, et al. The effect of obesity on pulmonary lung function of school aged children in Greece. Pediatr Pulmonol (2009) 44:273-80. doi:10.1002/ppul.20995

24. Ulger Z, Demir E, Tanaç R, Gökşen D, Gülen F, Darcan S, et al. The effect of childhood obesity on respiratory function tests and airway hyperresponsiveness. Turk J Pediatr (2006) 48:43-50.

25. Green M, Mead J, Turner JM. Variability of maximum expiratory flow-volume curves. J Appl Physiol (1974) 37:67-74.

26. Forno E, Weiner DJ, Mullen J, Sawicki G, Kurland G, Han YY, et al. Obesity and airway dysanapsis in children with and without asthma. Am J Respir Crit Care Med (2017) 195:314-23. doi:10.1164/rccm.201605-1039OC

27. Cole TJ, Freeman JV, Preece MA. British 1990 growth reference centiles for weight, height, body mass index and head circumference fitted by maximum penalized likelihood. Stat Med (1998) 17:407-29. doi:10.1002/(SICI) 1097-0258(19980228)17:4<407:AID-SIM742>3.0.CO;2-L

28. Cole TJ, Bellizzi MC, Flegal KM, Dietz WH. Establishing a standard definition for child overweight and obesity worldwide: international survey. BMJ (2000) 320:1240-3. doi:10.1136/bmj.320.7244.1240

29. Global Initiative for Asthma - GINA. Available from: http://ginasthma. org/2017-gina-report-global-strategy-for-asthma-management-and-prevention/

30. Liu AH, Zeiger R, Sorkness C, Mahr T, Ostrom N, Burgess S, et al. Development and cross-sectional validation of the Childhood Asthma Control Test. J Allergy Clin Immunol (2007) 119:817-25. doi:10.1016/j.jaci.2006.12.662

31. Oliveira SG, Sarria EE, Roncada C, Stein RT, Pitrez PM, Mattiello R. Validation of the Brazilian version of the childhood asthma control test (c-ACT). Pediatr Pulmonol (2016) 51:358-63. doi:10.1002/ppul.23318

32. Miller MR, Hankinson J, Brusasco V, Burgos F, Casaburi R, Coates A, et al. Standardisation of spirometry. Eur Respir J (2005) 26:319-38. doi:10.1183/ 09031936.05.00034805

33. Quanjer PH, Stanojevic S, Cole TJ, Baur X, Hall GL, Culver BH, et al. Multiethnic reference values for spirometry for the 3-95-yr age range: the global lung function 2012 equations. Eur Respir J (2012) 40:1324-43. doi:10.1183/ 09031936.00080312

34. Oostveen E, Boda K, Van Der Grinten CPM, James AL, Young S, Nieland H, et al. Respiratory impedance in healthy subjects: baseline values and bronchodilator response.EurRespirJ(2013) 42:1513-23. doi:10.1183/09031936.00126212

35. Nowowiejska B, Tomalak W, Radliński J, Siergiejko G, Latawiec W, Kaczmarski M. Transient reference values for impulse oscillometry for children aged 3-18 years. Pediatr Pulmonol (2008) 43:1193-7. doi:10.1002/ppul.20926

36. Lazovic-Popovic B, Zlatkovic-Svenda M, Durmic T, Djelic M, Djordjevic Saranovic S, Zugic V. Superior lung capacity in swimmers: some questions, more answers! Rev Port Pneumol (2016) 22:151-6. doi:10.1016/j. rppnen.2015.11.003
37. Konarski M, Klos R, Nitsch-Osuch A, Korzeniewski K, Prokop E. Lung function in divers. Adv Exp Med Biol (2013) 788:221-7. doi:10.1007/97894-007-6627-3_32

38. Llapur CJ, Martinez MR, Grassino PT, Stok A, Altieri HH, Bonilla F, et al. Chronic hypoxia accentuates dysanaptic lung growth. Am J Respir Crit Care Med (2016) 194:327-32. doi:10.1164/rccm.201509-1851OC

39. Weinmayr G, Forastiere F, Büchele G, Jaensch A, Strachan DP, Nagel G. Overweight/obesity and respiratory and allergic disease in children: international study of asthma and allergies in childhood (Isaac) phase two. PLoS One (2014) 9:e113996. doi:10.1371/journal.pone.0113996

40. Melo LC, da Silva MAM, Calles AC. Obesity and lung function: a systematic review. Einstein (Sao Paulo) (2014) 12:120-5. doi:10.1590/S167945082014RW2691

41. Santamaria F, Montella S, Greco L, Valerio G, Franzese A, Maniscalco M, et al. Obesity duration is associated to pulmonary function impairment in obese subjects. Obesity (2011) 19:1623-8. doi:10.1038/oby.2011.1

42. Bekkers MB, Wijga AH, Gehring U, Koppelman GH, de Jongste JC, Smit HA, et al. BMI, waist circumference at 8 and 12 years of age and FVC and FEV1 at 12 years of age; the PIAMA birth cohort study. BMC Pulm Med (2015) 15:39. doi:10.1186/s12890-015-0032-0

43. Strunk RC, Weiss ST, Yates KP, Tonascia J, Zeiger RS, Szefler SJ, et al. Mild to moderate asthma affects lung growth in children and adolescents. J Allergy Clin Immunol (2006) 118:1040-7. doi:10.1016/j.jaci.2006.07.053

44. Weiss ST, Tosteson TD, Segal MR, Tager IB, Redline S, Speizer FE. Effects of asthma on pulmonary function in children. A longitudinal population-based study. Am Rev Respir Dis (1992) 145:58-64. doi:10.1164/ajrccm/ 145.2_Pt_2.S58

45. McGeachie MJ, Yates KP, Zhou X, Guo F, Sternberg AL, Van Natta ML, et al. Patterns of growth and decline in lung function in persistent childhood asthma. N Engl J Med (2016) 374:1842-52. doi:10.1056/NEJMoa1513737

46. Den Dekker HT, Sonnenschein-Van Der Voort AMM, De Jongste JC, Anessi-Maesano I, Arshad SH, Barros H, et al. Early growth characteristics and the risk of reduced lung function and asthma: a meta-analysis of 25,000 children. J Allergy Clin Immunol (2016) 137:1026-35. doi:10.1016/j.jaci. 2015.08.050

47. Lanza FC, De Moraes Santos ML, Selman JPR, Silva JC, Marcolin N, Santos J, et al. Reference equation for respiratory pressures in pediatric population: a multicenter study. PLoS One (2015) 10:e0135662. doi:10.1371/ journal.pone.0135662

48. Pliakas T, McCarthy HD. Association of leg length with overweight and obesity in children aged 5-15 years: a cross-sectional study. Ann Hum Biol (2010) 37:10-22. doi:10.3109/03014460903092371

49. van de Kant KDG, Paredi P, Meah S, Kalsi HS, Barnes PJ, Usmani OS. The effect of body weight on distal airway function and airway inflammation. Obes Res Clin Pract (2015) 10:564-73. doi:10.1016/j.orcp.2015.10.005

50. Kalhoff H, Breidenbach R, Smith H-J, Marek W. Impulse oscillometry in preschool children and association with body mass index. Respirology (2011) 16:174-9. doi:10.1111/j.1440-1843.2010.01906.x

51. Lauhkonen E, Koponen P, Nuolivirta K, Paassilta M, Toikka J, Saari A, et al. Obesity and bronchial obstruction in impulse oscillometry at age 5-7 years in a prospective post-bronchiolitis cohort. Pediatr Pulmonol (2015) 50:908-14. doi:10.1002/ppul.23085

52. Galant SP, Komarow HD, Shin HW, Siddiqui S, Lipworth BJ. The case for impulse oscillometry in the management of asthma in children and adults. Ann Allergy Asthma Immunol (2017) 118:664-71. doi:10.1016/j.anai.2017. 04.009

Conflict of Interest Statement: The authors declare that the research was conducted in the absence of any commercial or financial relationships that could be construed as a potential conflict of interest.

Copyright (c) 2017 Jones, Roncada, Fernandes, Heinzmann-Filho, Sarria Icaza, Mattiello, Pitrez, Pinto and Stein. This is an open-access article distributed under the terms of the Creative Commons Attribution License (CC BY). The use, distribution or reproduction in other forums is permitted, provided the original author(s) or licensor are credited and that the original publication in this journal is cited, in accordance with accepted academic practice. No use, distribution or reproduction is permitted which does not comply with these terms. 